\title{
CONTROLE DA PROPORÇÃO AR/ COMBUSTÍVEL EM UM MOTOR COM TECNOLOGIA FLEX
}

Lucas Motta De Novaes ${ }^{1}$, Paulo Alexandre Pizará Hayashida ${ }^{1}$ Armando Antônio Maria Laganá $^{1}$ João Francisco Justo Filho ${ }^{1}$ e

Pedro de Castro Rossetti ${ }^{1,2}$

${ }^{1}$ Escola Politécnica da Universidade de São Paulo

${ }^{2}$ ETAS

\begin{abstract}
E-mails: 1novaes.motta@usp.br, paulo.hayashida@usp.br, jjusto@lme.usp.br,
\end{abstract}
lagana@1si.usp.br,pedro.rossetti@etas.com

\section{RESUMO}

O gerenciamento de um motor a combustão interna busca o compromisso entre performance, eficiência e baixos índices de emissão para automóveis. O controle da mistura ar/combustível tem impacto direto no funcionamento do motor, tanto para emissão de poluentes quanto no consumo especifico e potência entregues ao veículo [4]. Este aspecto torna-se mais relevante ainda para motores bicombustíveis, por possuírem parâmetros variantes com a composição do combustível utilizado. Atualmente tal controle utiliza um sensor de oxigênio de banda estreita, permitindo apenas que se trabalhe com seu transiente. Este artigo adota a solução de utilizar uma sonda lambda de banda larga, a fim de aplicar controle também fora de regimes estacionários de rotação do motor a partir de valores absolutos de realimentação. $\mathrm{O}$ fato de não haver uma referência que precise estar sempre em transição, que ocorre no caso da banda estreita, possibilita a imposição de uma referência alvo que não seja apenas estequiométrica. Aliado a este controle, é utilizado uma correção baseada na medida do teor de etanol do combustível a ser consumido, de forma a eliminar intervalos sub-operacionais necessários para adaptação à composição de combustível em reabastecimentos e flutuações. Ao final é apresentado uma análise dos resultados gerados [2].

\section{INTRODUÇÃO}

Nos últimos anos, a disponibilidade de combustíveis fósseis e as emissões de gases do efeito estufa aumentaram o interesse pelos biocombustíveis. $O$ etanol, misturado com a gasolina, melhora as propriedades para a operação de motores de combustão interna, tendo um forte impacto sobre o desempenho do motor e por este motivo tem tido uma aceitação cada vez maior.

Para usufruir dos benefícios da mistura do etanol combustível requer uma adaptação do controle ar-combustível (A/C) e do controle de ignição. O sistema de controle deve considerar as propriedades da mistura de combustível, seja através de medição direta ou por estimativa. Especialmente, devido às diferentes propriedades do etanol e da gasolina, a estrutura de controle $A / C$ deve ser adaptada à variabilidade do combustível 
de maneira online, o que convencionalmente não é aplicado para motores naturalmente aspirados. Este artigo apresenta uma das possíveis soluções que podem ser empregadas para auxiliar no controle da mistura ar/combustível em um motor Flex-fuel.

$\mathrm{Na}$ primeira seção tratar-se-ão os aspectos básicos referentes à relação $A / C$. $A$ segunda seção traz uma visão geral sobre o controle de formação da mistura $A / C$. A terceira seção descreve os métodos de correção e controle aplicados de forma prática. E por fim a quarta seção discute os resultados.

\section{RELAÇÃO AR-COMBUSTÍVEL}

Uma visão simplista da operação de um motor à combustão interna é que o motor mistura ar e combustível. Esta mistura $A / C$ é queimada liberando energia e trabalho através da expansão volumétrica dos gases e, como consequência desta produção de trabalho, tem-se as emissões de gases na atmosfera após o processo da combustão. A medida da mistura ar/combustível é importante tanto para a produção do trabalho quanto para o controle dos níveis de emissões.

\section{1. $\operatorname{Ar}$}

O ar é constituído por diferentes gases, que consistem em oxigênio, nitrogênio, argônio, dióxido de carbono, dentre outros. O oxigênio é essencial em um motor, o processo de oxidação libere energia na forma de calor. Os outros gases são inertes e possuem efeitos mínimos na combustão, porém, abancam calor e espaço na câmara de combustão. A proporção de distribuição em volume e em massa estão listadas na Tabela 1.

Tabela 1 - Discriminação dos diferentes gases que constituem o ar.

\begin{tabular}{|c|c|c|c|}
\hline Constituinte & Símbolo & Volume [\%] & Massa[\%] \\
\hline Oxigênio & $\mathrm{O}_{2}$ & 20.95 & 23.14 \\
\hline Nitrogênio & $\mathrm{N}_{2}$ & 78.09 & 75.53 \\
\hline Argônio & $\operatorname{Ar}$ & 0.93 & 1.28 \\
\hline Dióxido de carbono & $\mathrm{CO}_{2}$ & 0.03 & 0.05 \\
\hline
\end{tabular}

Fonte: [1]

Dos gases apresentados apenas o oxigênio é consumido pelo processo de combustão, o argônio, nitrogênio e o dióxido de carbono são expandidos de maneira elástica, gerando a pressão de trabalho para os motores de combustão interna.

\subsection{Combustíveis}

Os elementos químicos mais importantes dos combustíveis são o hidrogênio $\mathrm{H}$ e o carbono C, a junção entre os dois elementos é denominada como hidrocarboneto. Em alguns casos há a presença do oxigênio no combustível (caso dos álcoois). A maioria dos combustíveis para motores veiculares são hidrocarbonetos HC's, os quais permanecem em forma liquida sob condições 
atmosféricas [1]. Os combustíveis mais utilizados em motores à combustão interna que possuem sistema de ignição à centelha (SI - Sparked Ignition) são a gasolina e o etanol, e suas principais propriedades físico-químicas estão listadas na Tabela 2.

Tabela 2 - Propriedades físico-químicas dos combustíveis gasolina e etanol.

\begin{tabular}{|c|c|c|}
\hline Propriedade & Gasolina EO & Etanol \\
\hline $\begin{array}{l}\text { Concentração de } \\
\text { carbono/oxigênio (\%) }\end{array}$ & $86 / 0$ & $52 / 35$ \\
\hline Densidade a $15^{\circ} \mathrm{C}\left(\mathrm{kg} / \mathrm{m}^{3}\right)$ & 747 & 789 \\
\hline Resistência à detonação (RON) & 92 & 111 \\
\hline Calor de combustão (MJ/Kg) & 42.4 & 26.8 \\
\hline Ponto de ebulição $\left({ }^{\circ} \mathrm{C}\right)$ & $20-300$ & 78.5 \\
\hline Constante dielétrica & 2.0 & 24.3 \\
\hline
\end{tabular}

Fonte: [2] e [3]

\subsection{Relação $A / C$ estequiometria}

A relação $A / C$ expressa a proporção em massa ente 0 ar e a massa de combustível admitidos pelo motor para que haja a reação química de combustão.

$$
A / C=\frac{m_{a}}{m_{c}}
$$

Uma reação de combustão estequiométrica entre um combustível hidrocarboneto genérico $C_{a} H_{b}$ e ar, deve obter como produtos a água e o dióxido de carbono como expresso pela Eq. (2).

$$
C_{a} H_{b}+\left(a+\frac{b}{4}\right)\left(O_{2}+3.773 N_{2}\right) \rightarrow a C_{2}+\frac{b}{2} H_{2} O+3.773\left(a+\frac{b}{4}\right) N_{2}
$$

Com base no cálculo da Eq.(2). As relações $A / C$ estequiométricas são respectivamente definidas pelas Eqs. (3), (4) e (5) dos combustíveis gasolina E0RON95, gasolina E27 e etanol H100.

$$
\begin{gathered}
A / C_{\text {estequiométrica gasolina } E 0} \cong 14,6 \\
A / C_{\text {estequiométrica gasolin } E 27} \cong 12,5 \\
A / C_{\text {estequiométrica Etanol }} \cong 9,0
\end{gathered}
$$

As relações estequiométricas do etanol e da gasolina são, portanto, referências para o controle da mistura $\mathrm{A} / \mathrm{C}$. 


\section{TRATAMENTO DA RELAÇÂO A/C}

O controle da mistura ar/combustível de forma geral constitui-se por uma combinação entre o tratamento deste controle em ciclo aberto e o tratamento em ciclo fechado. $O$ controlador da mistura A/C corrige o cálculo da largura de pulso que aciona a válvula injetora de combustível, dosando assim, a massa de combustível, com as apropriadas compensações [4].

\subsection{Controle em ciclo aberto}

O ciclo aberto (feedforward loop) para controle da mistura ar/combustível determina a quantidade de combustível a ser injetada em função de uma estimativa de massa de ar realizada pelo sistema de admissão do ar. Esta é uma abordagem está esquematizada na Figura 1.

Figura 1- Diagrama de controle em malha aberta (feedforward loop).

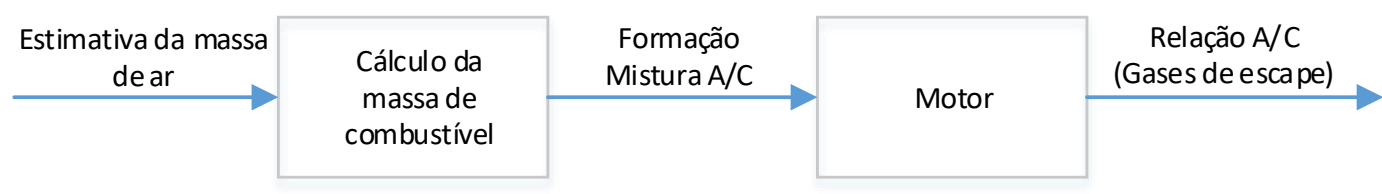

Fonte: $\mathrm{O}$ autor

\subsubsection{Estimativa da massa de ar}

A massa de combustível preliminar é requerida para que se mantenha a combustão na região estequiométrica em função do fluxo de ar e pressão no coletor de admissão. Geralmente seguem-se duas técnicas para se estimar o fluxo de ar para o cilindro de um motor SI. Uma delas é a estratégia speed density. A partir do sinal MAP (Manifold Absolute Pressure) a equação dos gases perfeitos de Clapeyron é empregada para estimar a massa do ar entrante de maneira indireta, correlacionando a massa de ar com a pressão do ar presente no coletor de admissão e eficiência volumétrica do motor.

A outra técnica é a medição direta do fluxo de ar através do sensor MAF (Manifold Air Flow). Para maiores informações consultar [1] e [4].

\subsection{Controle em ciclo fechado}

O ciclo fechado (feedback loop) de controle de formação da mistura A/C é formado pelo conjunto união entre as abordagens feedforward e feedback. O ciclo em malha aberta determina em primeira instancia o fluxo de combustível a ser consumido em função da quantidade de ar, o ciclo em malha fechada realiza correções de forma automática a fim de se alcançar uma determinada referência alvo. 
Figura 2 - Diagrama de controle em malha fechada (feedback loop).

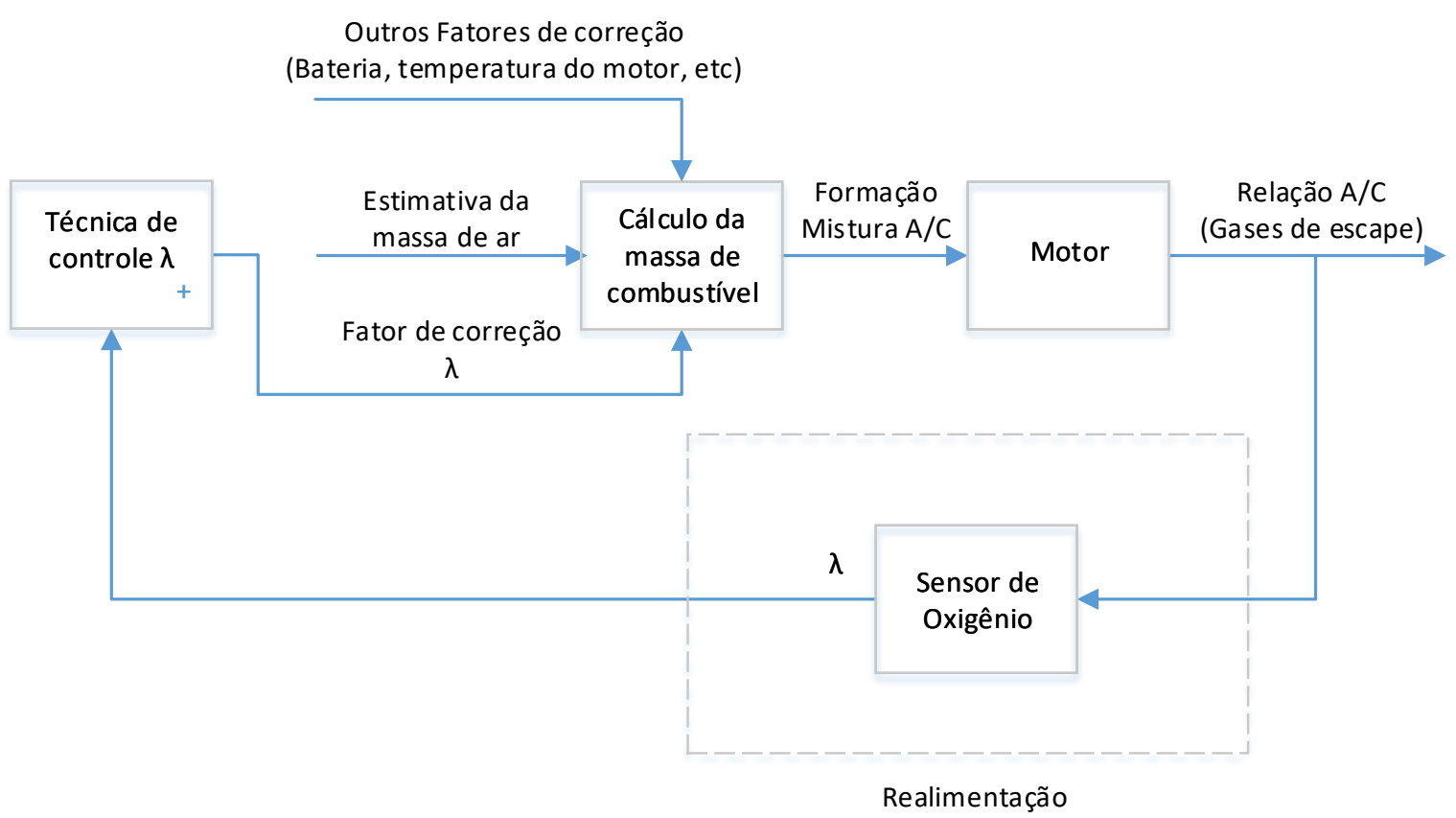

Fonte: O autor

Para os motores a combustão interna que empregam o ciclo Otto denominados como SI (Sparked Ignition), emprega-se o pós-tratamento para os gases de escape com um conversor catalítico de 3 vias o TWC (Three Way Catalystic). O principal objetivo do feedback loop é manter a relação $A / C$ resultante da queima dos gases em um estreito intervalo denominado janela estequiométrica, onde obtém-se a maior eficiência de conversão dos três principais gases poluentes (Figura 3).

Figura 3 - Representação da faixa de eficiência para conversão dos gases realizada por um catalisador de três vias.

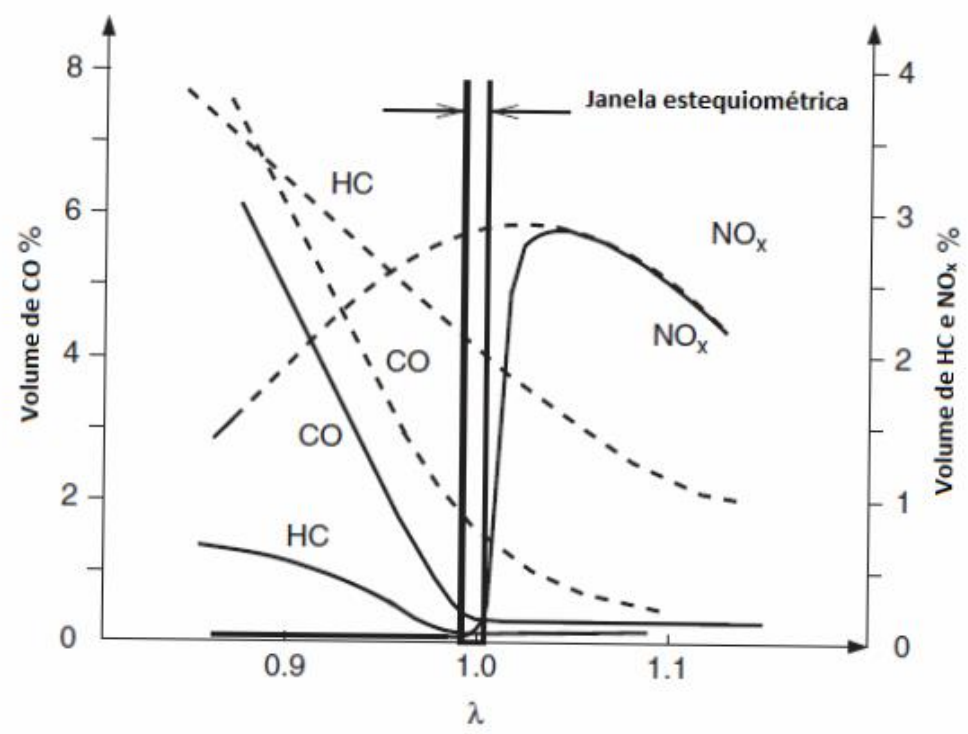

FONTE: Adaptado de [1] 


\subsubsection{O Sensor de oxigênio}

Os sensores empregados no monitoramento da relação $A / C$ medem o conteúdo de oxigênio nos gases de exaustão, para o qual é estabelecida uma relação $\lambda$. Para isto, a célula de Nernst é usada como elemento sensor. O princípio de medida é baseado na ideia de que na superfície do elemento sensor existe uma mudança de átomos de oxigênio para íons de oxigênio [1].

$$
O_{2}+4 e^{-} \leftrightarrow 2 O^{2-}
$$

Popularmente conhecido como sonda lambda, este sensor mede o teor de oxigênio presentes nos gases expelidos no sistema de escapamento após a queima da mistura $\mathrm{A} / \mathrm{C}$, correlacionando-a em uma relação $\lambda$ representada pela Eq. (7).

$$
\lambda=\frac{A / C_{\text {instantânea }}}{A / C_{\text {estequiométrica }}}
$$

O fator lambda é utilizado para que se possa determinar qual o estado da mistura consumida pelo motor. Quando o coeficiente lambda é menor do que $1(\lambda<1)$, a mistura é denominada rica, significando que a mistura atual possui mais combustível do que a quantidade ideal para reagir com o oxigênio, sendo que a parcela que não foi consumida será perdida.

Por outro lado, quando lambda é maior do que $1(\lambda>1)$, a mistura é denominada pobre, ou seja, a mistura atual possui uma quantidade maior de oxigênio do que a ideal para a reação com o combustível. Idealmente tem-se lambda igual a $1(\lambda=1)$, quando a mistura $\mathrm{A} / \mathrm{C}$ real é igual à mistura ideal, isto é, toda a mistura foi convertida pela reação quimica da combustão.

Utilizou-se um sensor de oxigênio de banda larga, devido a sua vasta aplicabilidade em motores de combustão interna, este tipo de sensor é denominado UEGO (Universal Exhaust Gas $\underline{\text { Ox}} x y g e n)$ ou LSU (Lambda Sonde Universal) na designação alemã.

Segundo [7], um sensor de banda larga, que utiliza o princípio de corrente limitante, gera uma força eletromotriz que é medida na forma de tensão, de acordo com a Eq.(8):

$$
U_{\lambda B L}=\mathrm{I}_{p} \mathrm{R}_{b}+\frac{R T}{4 F} \ln \frac{p_{O_{2}(\text { ambiente })}}{p_{O_{2}(\text { exaustão) }}}
$$

No entanto, a medida da relação lambda é realizada através da medição corrente de bombeamento $\mathrm{I}_{p}$, a Figura 4 mostra os pontos de calibração do sensor, que é realizada com gases específicos, sendo a função $f(x)$ uma interpolação linear entre estes pontos medidos. 
Figura 4 - Exemplo de calibração da corrente de bombeamento de um sensor broad/wide band em função da relação $\lambda$.

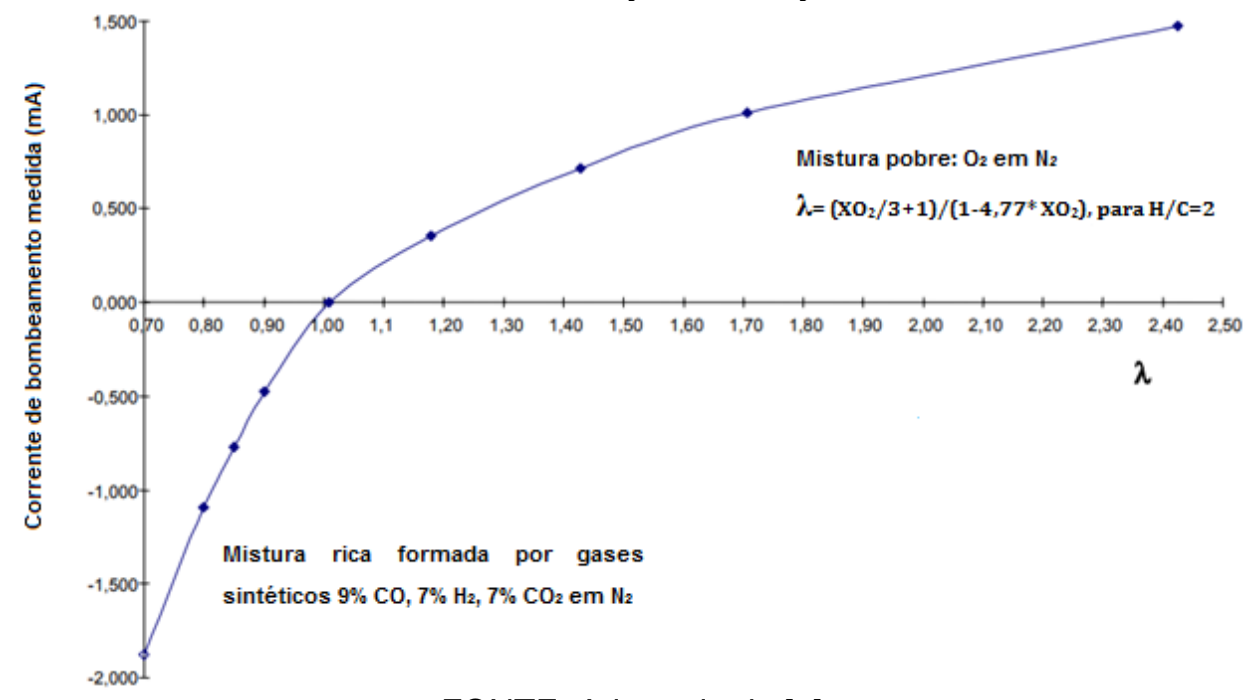

FONTE: Adaptado de [5]

\section{MÉTODOS UTILIZADOS}

\subsection{Controle A/C}

Um software de aplicação denominado Otto III foi desenvolvido em [6] para um motor 1.6l I4, utilizando a ferramenta ASCET no desenvolvimento lógico do gerenciamento, tendo como alvo a utilização da unidade de comando programável FlexECU.

Posteriormente, utilizou-se a proposta de uma correção feedforward em função da constituição do combustível, tratando-a em separado na forma de componentes gasolina e etanol, a partir da disponibilidade da medida de volume percentual do etanol para a ECU (Engine Control Unit). Com este método pôde-se realizar interpolação entre parâmetros ótimos tabelados para a gasolina E27 como para etanol hidratado $\mathrm{H} 100$.

$$
\begin{gathered}
a_{\text {ign }}=\left(\%_{\text {etanol }} a_{\text {ignetanol }}\right)+\left[\left(100 \%-\%_{\text {etanol }}\right) a_{\text {ign E27 }}\right] \\
t_{\text {inj }}=\left(\%_{\text {etanol }} t_{\text {inj etanol }}\right)+\left[\left(100 \%-\%_{\text {etanol }}\right) t_{\text {inj E27 }}\right]
\end{gathered}
$$

Os parâmetros corrigidos foram o avanço de ignição de forma concisa (limites conservadores por não haver correção de efeitos de knock) e o tempo de injeção de forma mais elaborada, suplementada pelo conjunto de controle de proporção da mistura A/C. Para mais informações acerca do sensor de volume de etanol consultar [2].

Figura 5 -Diagrama de cálculo de correção para tempos de injeção em função do combustível. 


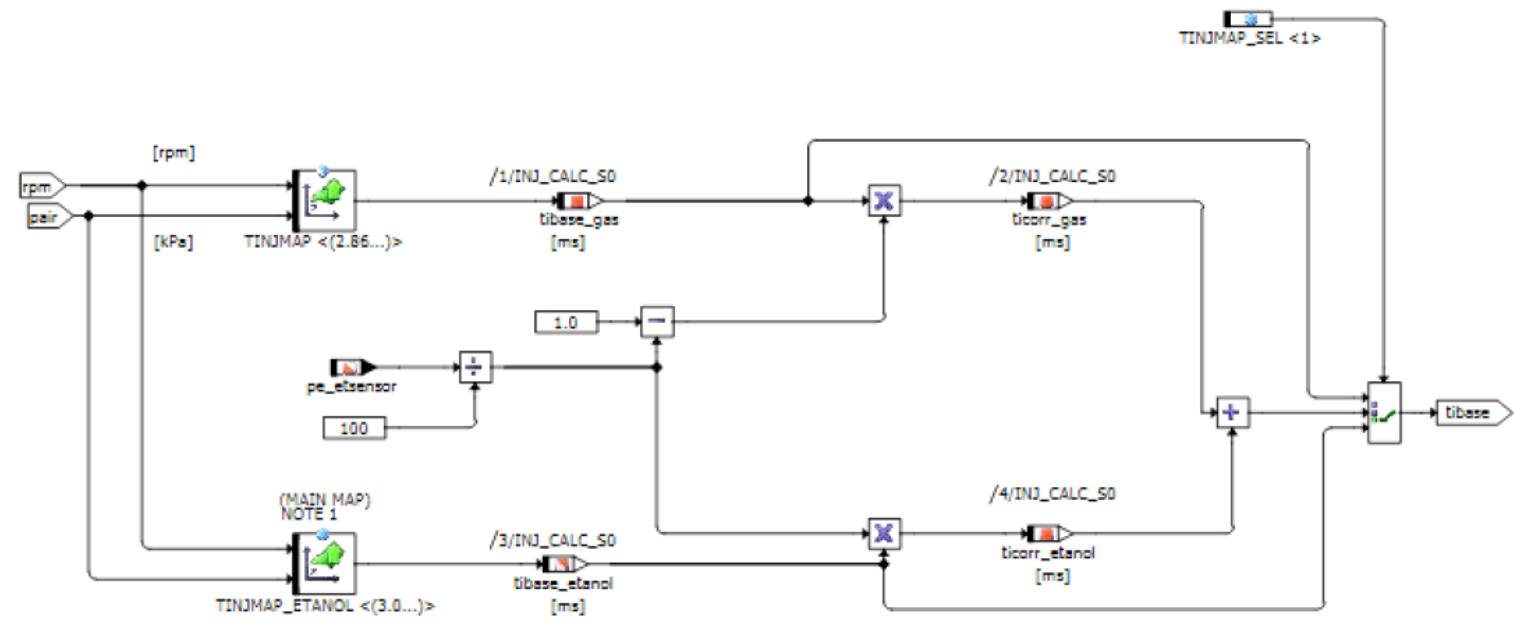

Fonte: O autor

Com o emprego da ferramenta de desenvolvimento ASCET (Advanced

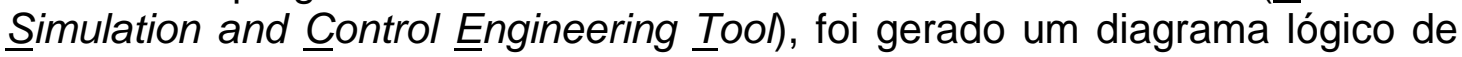
blocos que realiza as operações expressas pelas Eq. (9) (Figura 5).

De forma semelhante, a Figura 6 exibe diagrama de blocos que efetua a correção do avanço de ignição correspondente à Eq.(10).

Figura 6 - Diagrama de cálculo de correção para avanços de ignição em função do combustível.

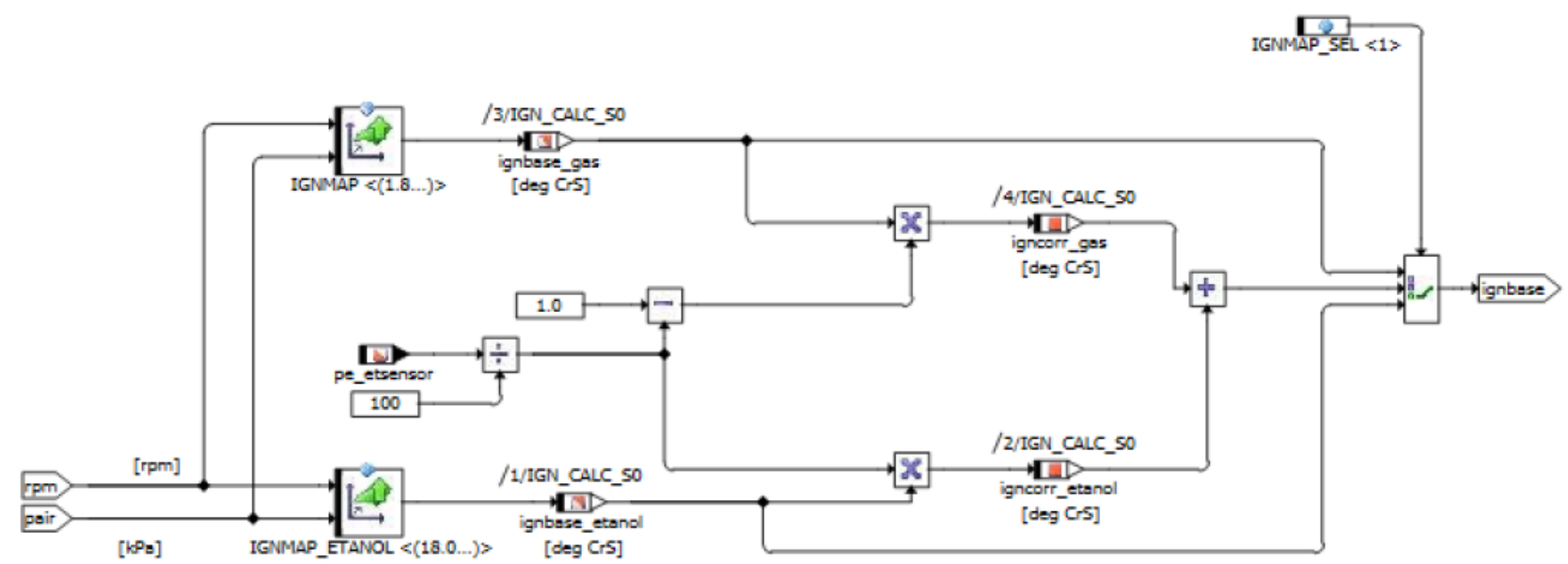

Fonte: O autor

Foram estipuladas condições inicias de teste para que a função do controle da relação lambda pudesse ser ativada, sendo: a medida da temperatura do liquido de arrefecimento ser superior a $50^{\circ} \mathrm{C}$, para não que não houvesse influencias sob os períodos de injeção durante enquanto o motor não estiver devidamente aquecido. Outro pré-requisito é que a rotação necessita ser superior a 600 RPM, liberando que o motor também seja alimentado com uma quantidade de combustível necessária durante o momento em que o $\mathrm{MCl}$ é 
rotacionado pelo motor de arranque no momento de partida. A Figura 7 exibe a estrutura de blocos utilizada do módulo lógico para controle da mistura $\mathrm{A} / \mathrm{C}$ em malha fechada, denominado $L A M B D A \_C A L C$.

Figura 7 - Diagrama do módulo lógico para controle $L A M B D A \_C A L C$.

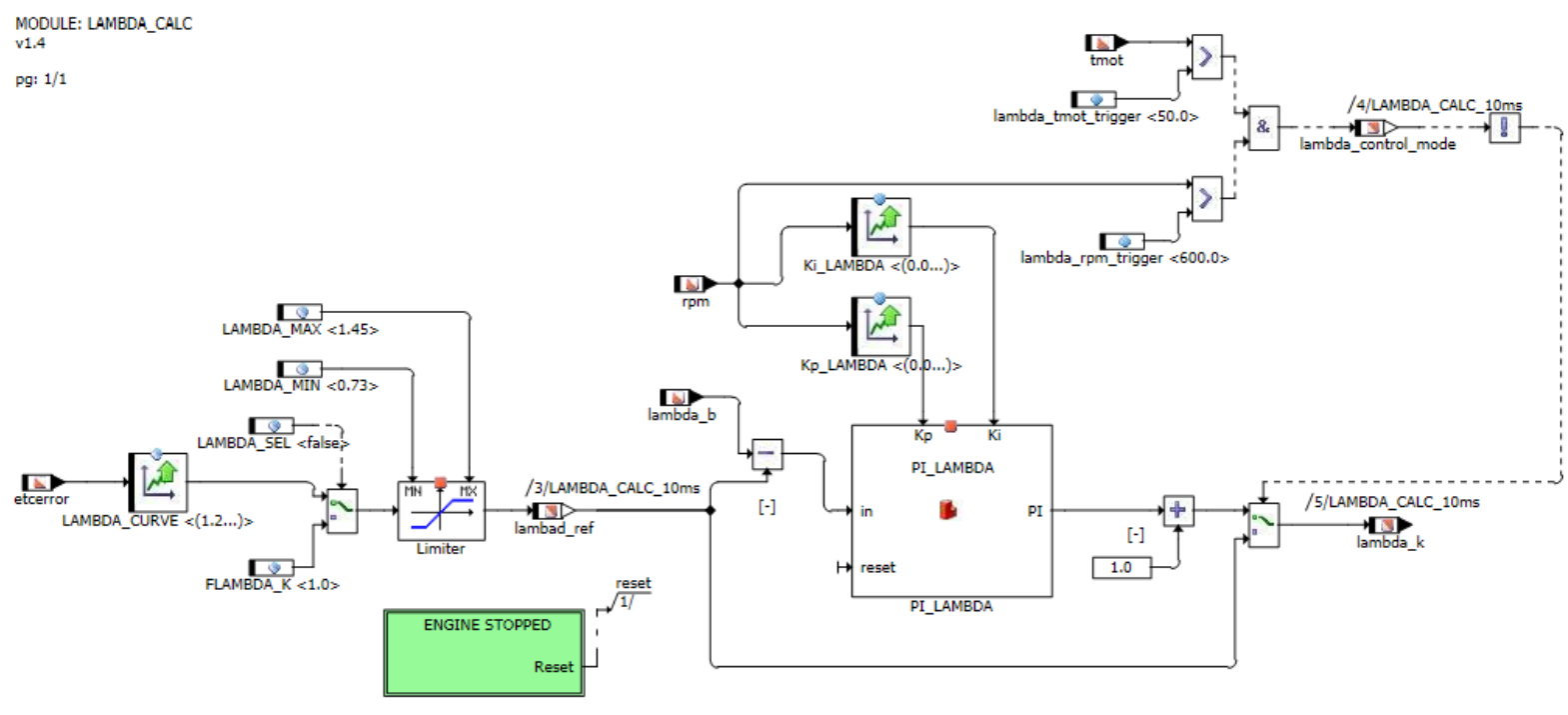

Fonte: O autor

A relação lambda é endereçada em função do sinal de erro do modulo de controle de rotação pelo mapa $\angle A M B D A \_C U R V E$. Os elementos deste mapa passam por um saturador que limita a excursões máxima e mínima da referência utilizada para o compensador $\mathrm{PI}$, que possui como saída um ganho multiplicativo que é o principal fator corretivo para o tempo de injeção. 


\section{RESULTADOS}

Nesta seção foram avaliados os efeitos de não se utilizar o método de interpolação para os parâmetros de controle no sistema de tratamento do controle da relação A/C. O intuito dos testes a seguir foi comparar o método utilizado de correção online em função do combustível com o efeito do período para adaptação do combustível em evento de reabastecimento. $O$ volume de etanol presente no combustível utilizado durante os testes foi de $59 \%$.

A operação e a obtenção de dados foram realizadas com o auxílio do sistema de

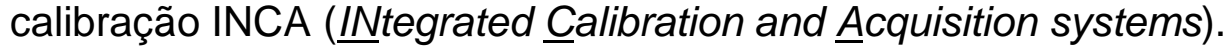

4.1. Teste de uma composição de combustível intermediária com parâmetros da gasolina E27

O tempo de injeção possui relação direta com a massa de combustível admitida pelo motor e consequentemente, com a relação ar combustível resultante. Foram pré-definidos os períodos de injeção (Figura 8) e avanços de ignição (Figura 9) relativos aos extremos que a composição do combustível poderia atingir (mapas base).

Figura 8 - Valores tabelados de tempo de injeção e saída interpolada (teste simulado para E27)

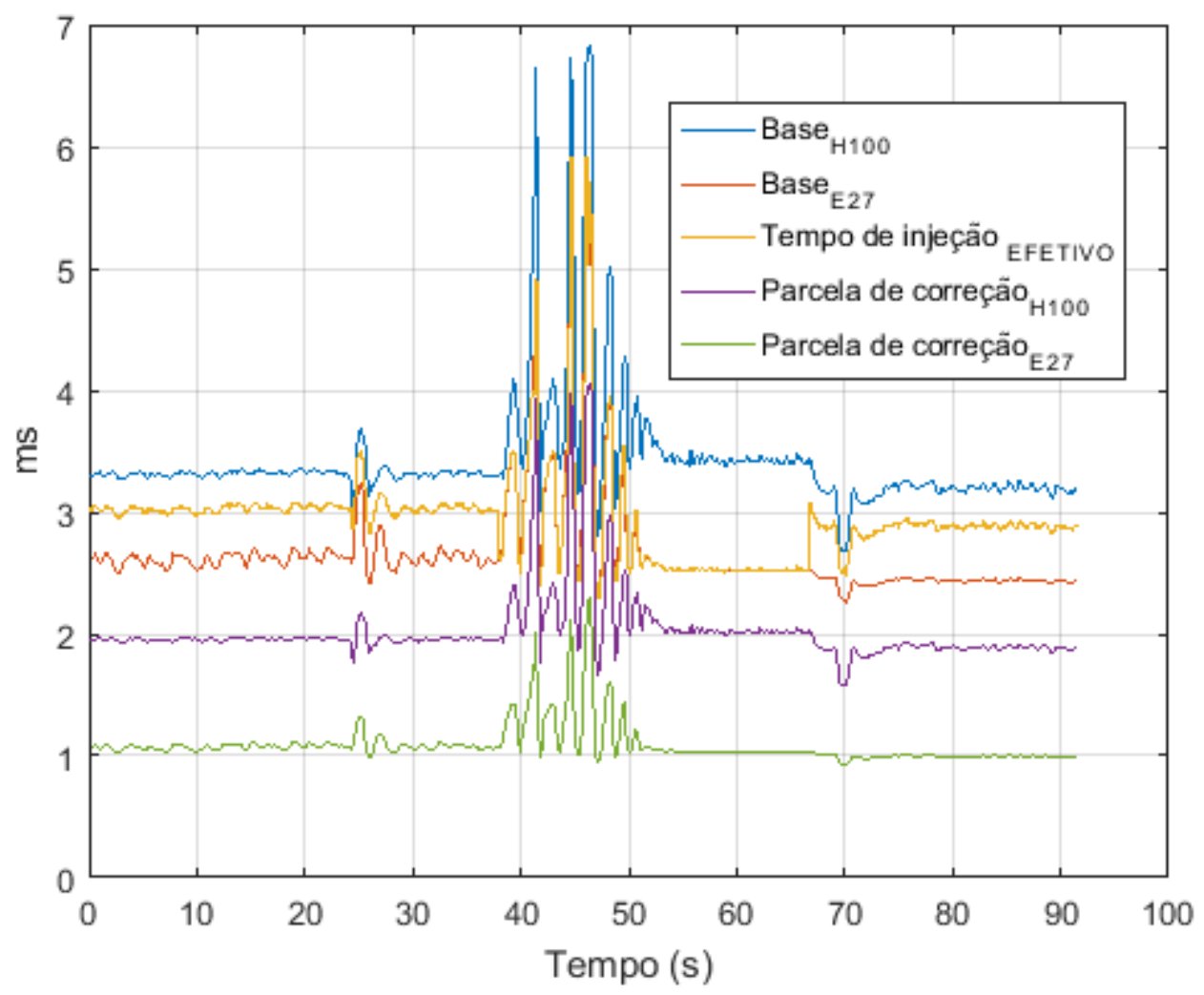

Fonte: $\mathrm{O}$ autor 
Figura 9 - Valores tabelados de avanço de ignição e saída interpolada (teste simulado para E27)

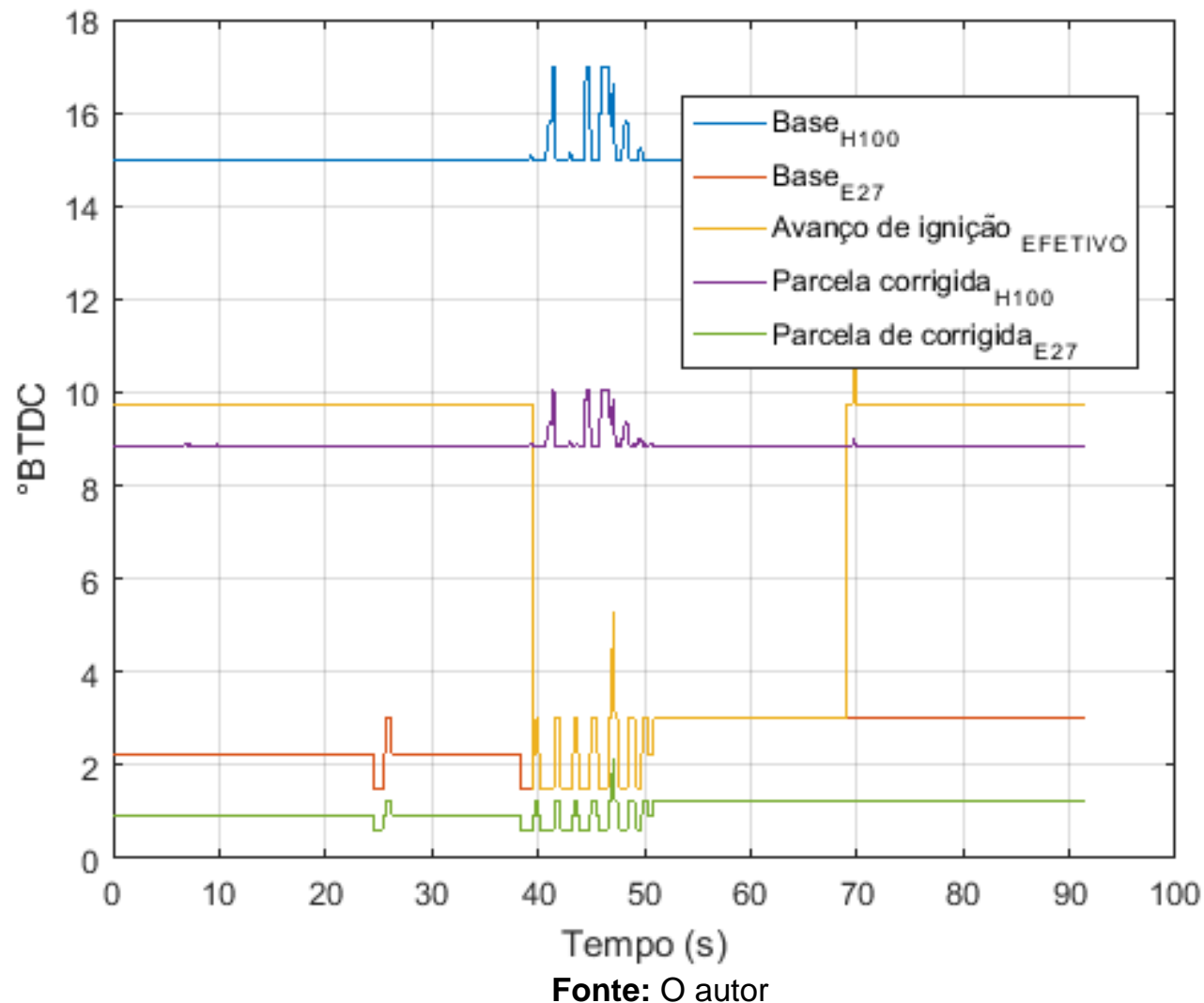

Na Figura 9 estão representados os avanços de ignição tabelados nos mapas base para gasolina E27, etanol Hidratado $\mathrm{H} 100$ e avanço de ignição correspondente à medida instantânea do teor de etanol do combustível que alimenta o motor, ou seja, aquele que está presente na galeria de combustível.

Durante a janela de 39 a 52 segundos, foram impostos forçadamente o avanço de ignição (Figura 9) e o tempo de injeção (Figura 8) para valores respectivos à gasolina, como efeito, observou-se através do fator de medição $\lambda$ (Figura 10) que no exato momento da transição da largura do pulso de injeção a mistura foi empobrecida devido a relação $\mathrm{A} / \mathrm{C}$ da gasolina ser maior que a do etanol e, portanto, demandar menos combustível para uma quantidade ar ser aproximadamente igual. 
Figura 10 - Sinal de saída e referência do controle A/C (teste simulado para E27)
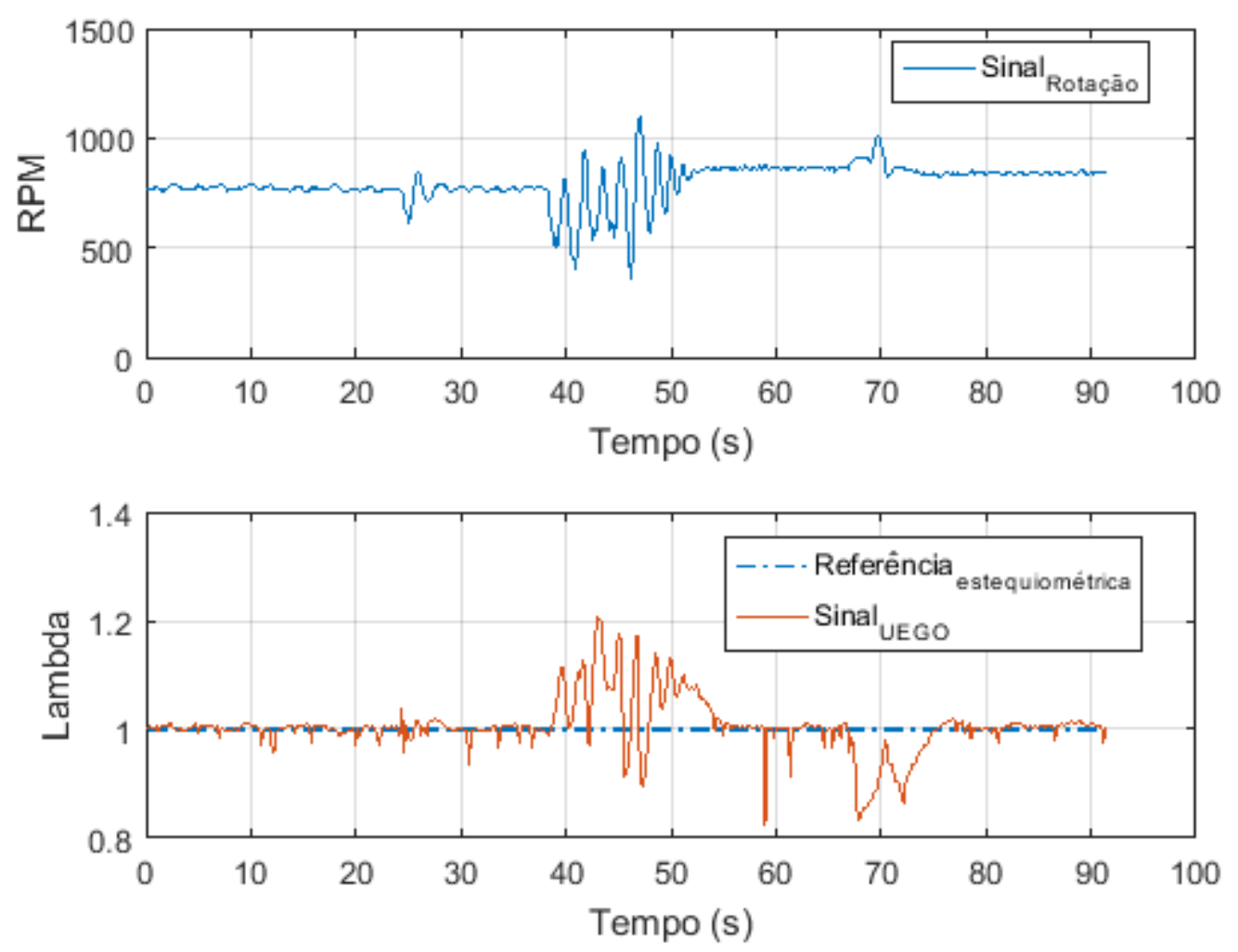

Fonte: $\mathrm{O}$ autor

Com isto obteve-se um comportamento oscilatório nos períodos de injeção e avanços de ignição em razão da não conformidade com o teor de etanol real do combustível. Posteriormente esse efeito foi compensado pelo controle da relação lambda após um período de 10 segundos. 
4.2. Teste de composição de combustível intermediária com parâmetros do etanol hidratado $\mathrm{H} 100$

Procedimento similar ao realizado na seção 4.1 foi repetido com o diferencial de simular um evento de reabastecimento anterior a uma adaptação feita ao etanol hidratado.

Figura 11 - Valores tabelados de tempo de injeção e saída interpolada (teste simulado para $\mathrm{H} 100)$

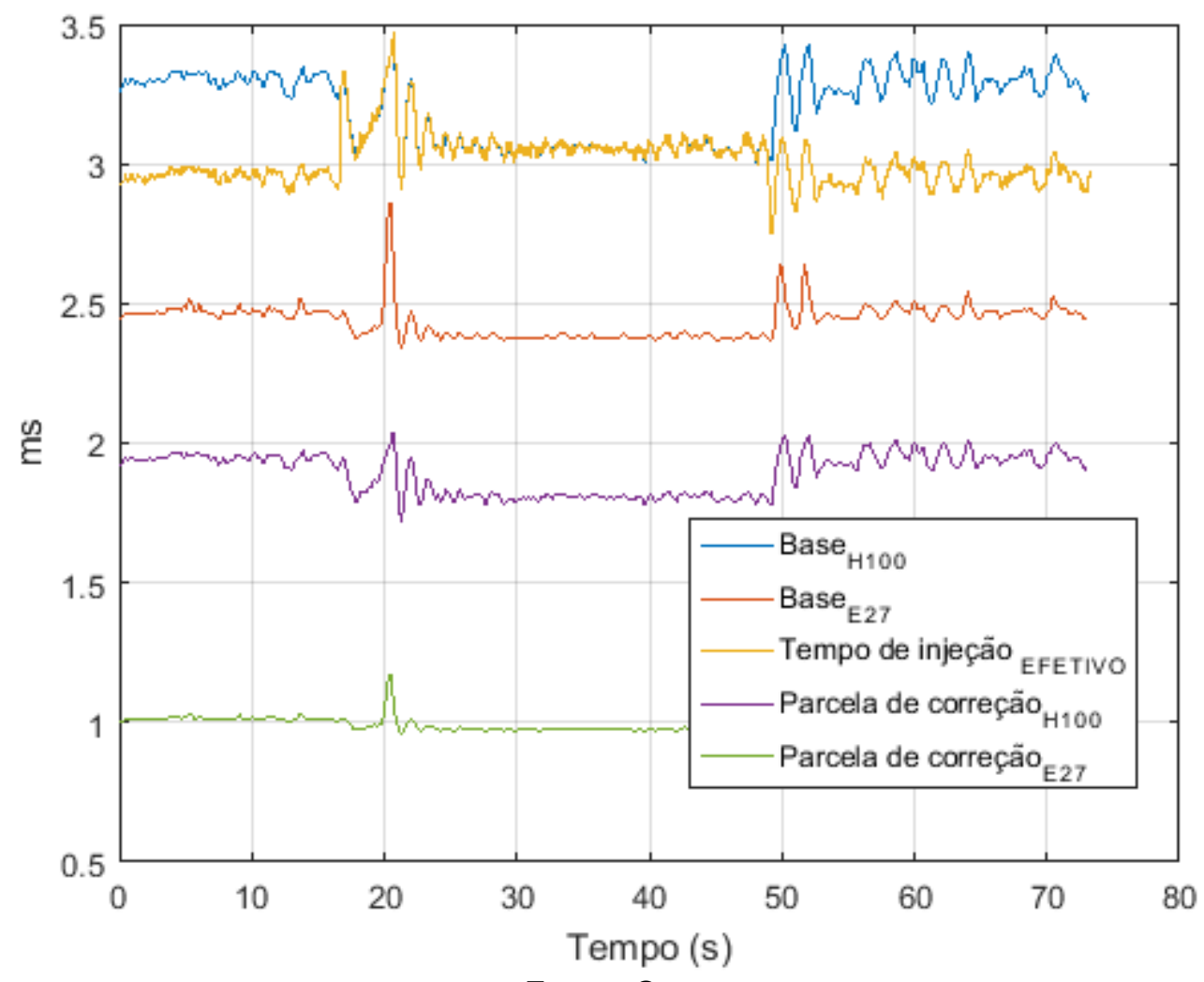

Fonte: $\mathrm{O}$ autor

A Figura 11 exibe os tempos de injeção sendo forçados para a referência do etanol hidratado, exemplificando a mudança no teor de etanol quando a mistura estaria adaptada para o etanol. 
Figura 12 - Valores tabelados de avanço de ignição e saída interpolada (teste simulado para $\mathrm{H} 100)$

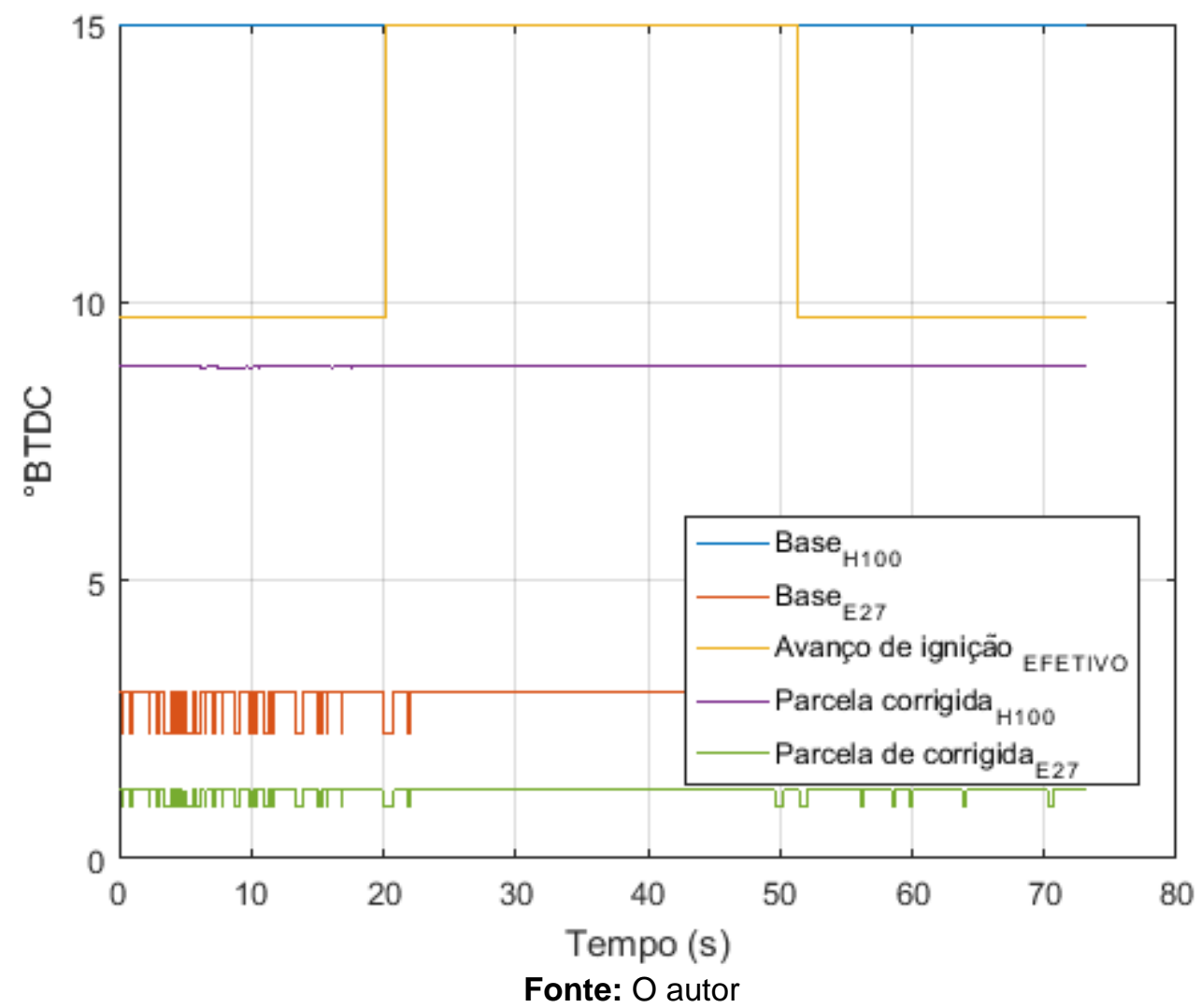

No espaço do período de 20 a 50 segundos, foram impostos forçadamente o avanço de ignição (Figura 12) e o tempo de injeção (Figura 11) para valores respectivos à gasolina, como efeito, observou-se através do fator de medição $\lambda$ (Figura 13) que no instante de mudança da largura de pulso da injeção a mistura foi enriquecida devido a relação $A / C$ estequiométrica para o etanol ser inferior à da gasolina e, portanto, demandar mais combustível para a mesma quantidade massa de ar. 
Figura 13 - Sinal de saída e referência do controle A/C (teste simulado para H100)

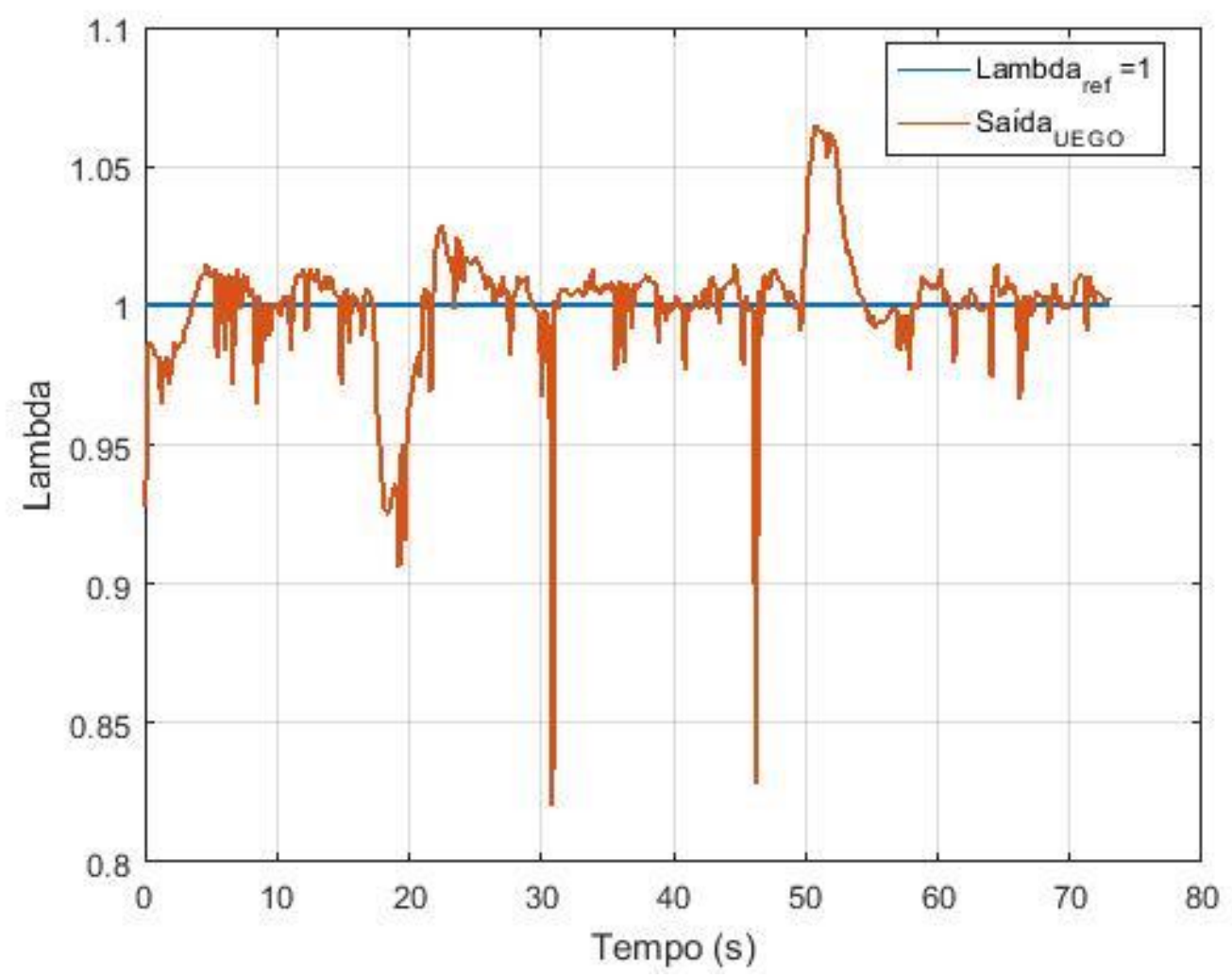

Fonte: O autor

\subsection{Teste de mudança de referência em aceleração brusca (kickdown)}

O principal objetivo deste experimento era observar se o laço de controle de lambda, mesmo estando ativo se adequaria a uma repentina demanda de torque. A partir do sinal de excitação para o controle de rotação do motor através do sistema EGAS (acelerador eletrônico). A rotação foi incrementada da condição de marcha lenta (800 RPM) até a rotação de 5200 RPM, momento em que o sinal do pedal foi devolvido à condição de repouso para que ocorra a desaceleração e reestabelecimento da condição de marcha lenta 
Figura 14 - Saída de rotação em regime de aceleração e sinal de medição relação lambda.
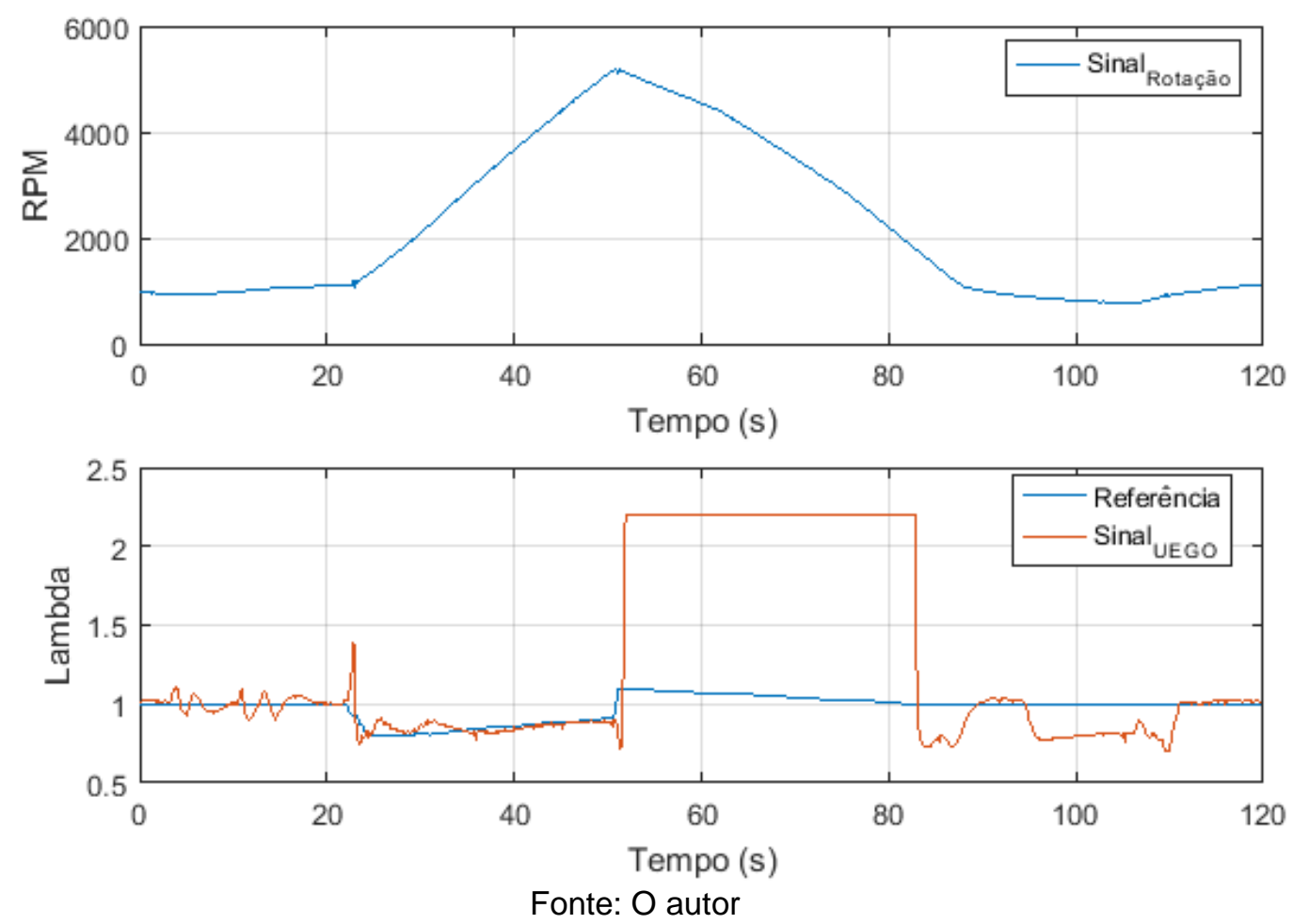

Na medição lambda exibida pela Figura 14durante os instantes iniciais a rotação do motor encontrava-se em regime de marcha lenta com uma relação lambda que oscilava em torno de sua referência estequiométrica. $O$ valor da relação lambda começa a ser alterado no instante de 25 segundos, o sinal medido passa a ser o de uma mistura enriquecida aos 27 segundos quando o sinal se torna empobrecido durante 30 segundos e posteriormente retorna ao ponto estequiométrico.

A diferença entre as rotações de referência e de saída constitui o erro do módulo ETC. Durante um regime transitório de rotação, a referência lambda torna-se dependente desse erro. Na detecção de um erro positivo pelo controle de rotação, é interpretada uma solicitação de aceleração. Através do sinal de pedal eletrônico, o ganho de enriquecimento da mistura endereçado, como efeito primário obtémse 0 aumento da vazão de ar devido a rápida abertura aplicada na válvula borboleta, o que torna a mistura pobre durante este primeiro momento, após isto, a malha de controle detecta a alteração da referência a ser seguida, e o período de injeção é maximizado pela ação de controle para obtenção do enriquecimento da mistura com o aumento do fluxo de combustível para os cilindros, resultando em reações de combustões mais carregadas do ponto de vista energético, com a finalidade de acréscimo da rotação do motor e consequentemente do seu torque de saída. Quando o erro de rotação se torna negativo, obtém -se o processo inverso, a referência desejada para a relação lambda é atingir uma mistura empobrecida, para auxiliar na desaceleração do veículo, contribuindo em conjunto com a estratégia de cut-off para aplicação do chamado "freio motor" com a finalidade de se evitar sobressinais na aceleração do motor 


\section{CONCLUSÃO}

Ainda não foram realizados testes de emissões e nem estão sendo considerados ciclos de regeneração para o conversor catalítico devido à tecnologia do TWC não requerer tais procedimentos, porém, estima-se que as emissões estejam em níveis relativamente baixos em razão da referência estequiométrica, onde ocorre a maior eficiência das conversões catalíticas realizadas por um TWC.

Este artigo demonstrou uma abordagem para gerenciamento da mistura ar/combustível em um motor Flex-fuel, exemplificando como pode ser eliminado o tempo de adequação dos parâmetros de combustão na variância do tipo de combustível utilizado; e foi abordada uma aplicação de correção dos parâmetros de controle da combustão em função da composição de combustível

\section{REFERÊNCIAS}

[1] ERIKSSON, Lars; NIELSEN, Lars. Modeling and control of engines and drivelines. United Kingdom: John Wiley and Sons, 2014.

[2] MCKAY, B.; VANVELZEN, I.; GUTH, C.; ACHLEITNER, E.; BIBER, P. An Onboard Ethanol Concentration Sensor for the Brazilian Market. SAE Technical Papers Series, 2012.

[3] AHN, Kyung-ho; STEFANOPOULOU, Anna G. Estimation of ethanol content in flexfuel vehicles using an exhaust gas oxygen sensor. IEEE International conference on control applications,2011.

[4] ASHOK, B.; DENIS ASHOK, I.; RAMESH KUMAR. A review on control system architecture of a SI Engine management system. Annual review in control, 2012.

[5]ROSSETTI, P. C.; SANTOS, J.P.F. Otto III by FlexECU - Gerenciamento Eletrônico de um Motor VW 1.6L. Universidade de São Paulo, 2015.

[6] BOSCH. Planar Wide Band Lambda Sensor LSU 4.9. 2005. pp. 1-13, Technical product information. 2005.

[7] LEE, Jong Heun. Review on zirconia air-fuel ratios for automotive applications. JOURNAL OF MATERIALS SCIENCE. 2003, Vol. 38, 21, pp. 4247-4257. 2003. 